\title{
DESENVOLVIMENTO DE MASSA DE REVESTIMENTO CERÂMICO UTILIZANDO MATÉRIAS-PRIMAS DA REGIÃO PARAÍBA/PERNAMBUCO
}

\author{
J. Q. GALVÃO NETO ${ }^{1}$, F. A. M. ARAÚJO ${ }^{1}$, S.M. S. MARIZ ${ }^{1}$, K. S. M. G. SOUZA ${ }^{1}$, G. Z. \\ CLERICUZI $^{1}$ \\ ${ }^{1}$ Universidade Federal da Paraíba, Departamento de Engenharia Química \\ E-mail para contato: joaodequeiroz@msn.com, sillasmatheus2010@hotmail.com, \\ karlasilvana@gmail.com, clericuzi.zc@gmail.com
}

\begin{abstract}
RESUMO - A seleção de matérias-primas é a etapa mais importante no desenvolvimento de formulações de massas de revestimentos cerâmicos, por ser um fator determinante para se obter a massa adequada ao processo produtivo e que também atenda as características técnicas desejadas. Portanto, o objetivo do presente trabalho é avaliar as características das matérias-primas e formulações das massas cerâmicas obtidas na região Paraíba/Pernambuco. Foram desenvolvidas três massas cerâmicas, variando a proporção de matéria-prima plástica, não plástica e fundente. Os resultados obtidos mostram que quanto maior a quantidade de material não-plástico, maior será a absorção de água e a resistência mecânica do produto final. Observou-se que é necessário um maior controle da escolha das matérias-primas, igualmente das suas percentagens nas formulações a fim de otimizar os resultados das propriedades físicas desejadas das massas cerâmicas desenvolvidas.
\end{abstract}

\section{INTRODUÇÃO}

Devido ao crescimento da indústria cerâmica e econômico na região nordeste do Brasil nos últimos anos, utilizar matérias-primas regionais para o desenvolvimento de novos produtos cerâmicos é de grande importância. Os revestimentos cerâmicos possuem características químicas, tamanho, formato, propriedades mecânicas, entre outros, bastante diversificados. Para a obtenção de propriedades específicas e a necessidade de diminuir os custos, é necessário um estudo das matérias-primas disponíveis a serem utilizadas na formulação das massas cerâmicas. Em geral, as massas cerâmicas para revestimentos por via seca do tipo semi-porosa (BIIb), são constituídas por matérias-primas plásticas, não-plásticas e fundentes, podendo uma mesma matéria-prima assumir uma ou mais destas funções, como mostrado no trabalho de Oliveira e Hotza (2011).

Segundo Gomes (2008), as matérias-primas plásticas são aquelas que conferem importantes características na fase de conformação das peças cerâmicas, tais como plasticidade, resistência mecânica a cru, e na sinterização, estrutura e cor. Argilas e caulins são as principais matérias-primas plásticas utilizadas em revestimentos cerâmicos semiporosos. Já as matérias-primas não plásticas, elas atuam nas fases de conformação e secagem, diminuindo a retração, favorecendo a secagem e a fase de queima, quando desempenham o papel mais relevante. Devido principalmente ao seu papel na fase de queima, os materiais 
não-plásticos são ainda qualificados de inertes e fundentes. As principais matérias-primas não plásticas utilizadas em revestimentos cerâmicos porosos são o quartzo e os carbonatos (cálcio e magnésio).

O objetivo principal do presente trabalho é o desenvolvimento de uma massa cerâmica que utilize matérias-primas disponíveis na região Paraíba/Pernambuco, que é onde se concentra um grande pólo de indústria cerâmica na região nordeste do país.

\section{MATERIAIS E MÉTODOS}

\subsection{Seleção e Classificação das Matérias-primas}

A seleção das matérias- primas para a fabricação de massas cerâmica é a etapa inicial, já que cada matéria-prima oferece uma característica funcional no corpo cerâmico. As matérias primas utilizadas no presente trabalho foram cedidas por uma indústria fabricante de revestimentos cerâmicos, situada na região metropolitana de João Pessoa/PB.

A Tabela 1 mostra a função de cada matéria-prima utilizada e a sua codificação correspondente.

Tabela 1 - Função de cada matéria-prima utilizada (EMILIANI, CORBARA 1999, modificado).

\begin{tabular}{|c|c|c|}
\hline Codificação & Nomenclatura & Função \\
\hline \hline AP-1 & Argila Plástica & $\begin{array}{c}\text { Componente Plástico / Dá coesão } \\
\text { e solidez à massa verde e crua. É } \\
\text { responsável pela retração durante } \\
\text { a secagem }\end{array}$ \\
\hline NP-1 & Material Não & $\begin{array}{c}\text { Componente fundente / Abaixa a } \\
\text { temperatura que se forma a fase } \\
\text { vítrea, que é responsável pela } \\
\text { fusão do componente } \\
\text { plástico/assegura a resistência } \\
\text { mecânica e coesão do produto }\end{array}$ \\
\hline F-1 & Fundente & \multicolumn{2}{|c}{} \\
\hline
\end{tabular}

\subsection{Caracterização das Matérias-primas}

As matérias-primas utilizadas no presente trabalho foram caracterizadas pela técnica de Análise Química por Fluorescência de Raios X (FRX).

\subsection{Formulação}

A preparação das composições das formulações foi realizada com base nas formulações utilizadas pelas indústrias de fabricação de pisos e revestimentos encontradas na literatura. Sendo assim, a partir das características, propriedades e composição química de cada matéria-prima realizou-se a formulação de 3 massas, como mostra na Tabela 2. 
Tabela 2 - Composição das formulações das massas estudadas

\begin{tabular}{|c|c|c|c|}
\hline \multirow{2}{*}{ Formulação } & \multicolumn{3}{|c|}{ Concentração em peso (\%) } \\
\cline { 2 - 4 } & AP-1 & NP-1 & F-1 \\
\hline \hline M-1 & 70 & 13 & 17 \\
\hline M-2 & 65 & 18 & 17 \\
\hline M-3 & 60 & 23 & 17 \\
\hline
\end{tabular}

\subsection{Moagem por via seca}

As matérias-primas e as formulações previamente estabelecidas passaram pelo processo de moagem por via seca, onde cada uma foi moída por 15 minutos em moinho periquito, com jarros e bolas de alumina da Servitech.

\subsection{Granulação, Conformação e Secagem}

Após a moagem, as massas foram passadas em peneira de 35 mesh e então adicionadas $7 \%$ de água com o objetivo de auxiliar o processo de prensagem do corpo de prova. Os corpos de prova confeccionados foram do tipo prismáticos (barras) com dimensões de $70 \mathrm{~mm}$ x $140 \mathrm{~mm}$ x $8 \mathrm{~mm}$ por prensagem a $275 \mathrm{Kgf} / \mathrm{cm}^{2}$ em prensa manual.

Após a etapa de conformação, os corpos de prova foram então secos em estufa durante $24 \mathrm{~h}$ com temperatura de $170{ }^{\circ} \mathrm{C}$, para a retirada da umidade adicionada na etapa de conformação.

\subsection{Sinterização/Queima}

As matérias-primas e as formulações foram submetidas à queima em forno industrial com temperatura máxima inferior da zona de queima de $1168{ }^{\circ} \mathrm{C}$ e temperatura máxima superior de $1158^{\circ} \mathrm{C}$ em ciclo de 26 minutos.

\subsection{Propriedades físicas}

Após a etapa de queima, todos os corpos de prova submetidos aos seguintes ensaios de determinação das propriedades tecnológicas: retração linear de queima (RL), perda ao fogo (PF), absorção de água (AA) e carga de ruptura queimado (CR)

\section{RESULTADOS}

\subsection{Análise Química por FRX}

A análise química das matérias-primas que foram estudadas é apresentada na Tabela 3. 


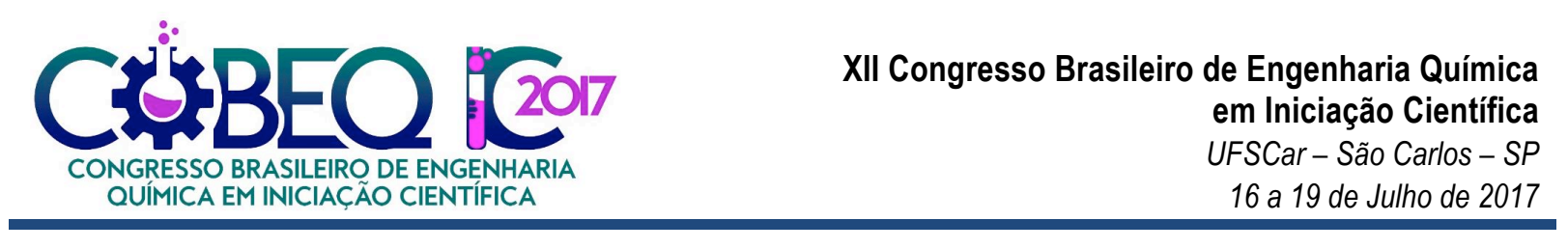

Tabela 3 - Composição química das matérias-primas utilizadas

\begin{tabular}{|c|c|c|c|}
\hline \multirow{2}{*}{$\begin{array}{c}\text { Óxido } \\
\text { Constituintes }\end{array}$} & \multicolumn{3}{|c|}{ Concentração em peso (\%) } \\
\cline { 2 - 4 } & $\mathrm{AP}-1$ & $\mathrm{NP}-1$ & $\mathrm{~F}-1$ \\
\hline $\mathrm{SiO}_{2}$ & 65,12 & 54,34 & 49,89 \\
\hline $\mathrm{Al}_{2} \mathrm{O}_{3}$ & 16,43 & 13,48 & 7,06 \\
\hline $\mathrm{Fe}_{2} \mathrm{O}_{3}$ & 5,34 & 12,36 & 8,3 \\
\hline $\mathrm{CaO}$ & 0,11 & 7,52 & 3,42 \\
\hline $\mathrm{MgO}$ & 1,59 & 5,11 & 23,43 \\
\hline $\mathrm{SO}$ & 0,03 & 0,22 & 0,02 \\
\hline $\mathrm{Na}_{2} \mathrm{O}$ & 0,33 & 3,48 & 0,37 \\
\hline $\mathrm{K}_{2} \mathrm{O}$ & 2,96 & 0,74 & 0,04 \\
\hline $\mathrm{TiO}_{2}$ & 0,86 & 2,76 & 0,26 \\
\hline
\end{tabular}

Conforme mostra na Tabela 3, AP-1 é basicamente constituída de $\mathrm{SiO}_{2}, \mathrm{Al}_{2} \mathrm{O}_{3}$ e $\mathrm{Fe}_{2} \mathrm{O}_{3}$. O óxido de alumínio, normalmente, indica a presença do mineral caulinita. Já o teor de óxidos fundentes, $\mathrm{Na}_{2} \mathrm{O}, \mathrm{CaO}$ e $\mathrm{MgO}$, foram menores em AP-1 do que em NP-1 e F-1, comprovando o fato de que ambos são utilizados como componente fundente na formulação da massa. NP-1 possui alto teor de $\mathrm{CaO}$ em sua composição, segundo Sousa e Holanda (2005), isso está relacionado à presença de carbonato de cálcio $\left(\mathrm{CaCO}_{3}\right)$, presente no calcário; a presença de carbonatos na massa cerâmica é de fundamental importância, pois garante a porosidade desejada e estabilidade dimensional. Todas as amostras das matérias-primas utilizadas obtêm teor de $\mathrm{Fe}_{2} \mathrm{O}_{3}$ superior a 3\%, conferindo ao produto final uma cor de queima avermelhada mais escura, como mostrado no trabalho de Dutra et al. (2005); observa-se também que a amostra de NP-1 apresenta um teor de $\mathrm{Fe}_{2} \mathrm{O}_{3}$ muito maior comparado ao AP-1 e F-1, sendo também função da adição do NP-1 na formulação da massa, que é obter um determinado tom de cor avermelhada característica.

\subsection{Propriedades Físicas}

As propriedades físicas das matérias-primas e das formulações estudadas estão apresentadas na Tabela 4 e 5 respectivamente. 
Tabela 4 - Propriedades Físicas analisadas das matérias-primas

\begin{tabular}{|c|c|c|c|}
\hline $\begin{array}{c}\text { Propriedade } \\
\text { Física }\end{array}$ & AP-1 & NP-1 & F-1 \\
\hline \hline RL (\%) & 6,3 & 6,26 & 2,1 \\
\hline $\mathrm{PF}(\%)$ & 5,1 & 4,0 & 5,6 \\
\hline
\end{tabular}

Tabela 5 - Propriedades Físicas das formulações estudadas

\begin{tabular}{|c|c|c|c|}
\hline $\begin{array}{c}\text { Propriedade } \\
\text { Física }\end{array}$ & M-1 & M-2 & M-3 \\
\hline \hline RL (\%) & 4,04 & 3,49 & 3,47 \\
\hline PF (\%) & 4,14 & 4,09 & 4,26 \\
\hline AA (\%) & 7,72 & 9,27 & 8,93 \\
\hline CR (N) & 589,48 & 473,38 & 622,65 \\
\hline
\end{tabular}

Através da análise das propriedades físicas das formulações estudadas no presente trabalho, observa-se na tabela 5 que a variação das proporções das matérias-primas não afetou os resultados de retração linear (RL\%) e perda ao fogo (PF\%) significativamente. No entanto, os resultados das análises de absorção da água (AA\%) e carga de ruptura (CR) mostram que com o aumento da quantidade de NP-1 na formulação, aumentou-se a capacidade de absorção de água devido ao fato de que materiais não plásticos aumentam a porosidade, assim como, aumentam a resistência do produto final. Uma outra observação feita, foi a aparição de coração negro nas formulações M-2 e M-3, sendo na M-3 muito mais significativa. Isso implica dizer que quando se aumentou a porcentagem da matéria-prima NF-1 e consequentemente diminuiu a de AR-1, aumentou-se a região do coração negro na massa cerâmica. Segundo Damiani et al. (2001), o aparecimento de coração negro está relacionado à presença de matéria orgânica e óxido de ferro na composição das matérias-primas da formulação da massa; esse comportamento é explicado devido à que o NP-1 contém alto teor de $\mathrm{Fe}$ e $\mathrm{C}$ em sua composição.

\section{CONCLUSÕES}

Conclui-se que, embora todas as formulações estarem de acordo com a NBR 13818 (ABNT, 1997) para revestimento do tipo BIIb, as formulações M-1 e M-3 se saíram melhor nos resultados analisados, devido ao aparecimento do coração negro na formulação M-3 e não na M-1, a melhor formulação desenvolvida no presente trabalho foi a M-1. 


\section{REFERÊNCIAS}

ASSOCIAÇÃO BRASILEIRA DE NORMAS TÉCNICAS - ABNT. NBR 13818: Placas Cerâmicas para Revestimento - Especificação e Métodos de Ensaios. Rio de Janeiro: ABNT, 1997.

DAMIANI, J. C.; PEREZ, F.; MELCHIADES, F. G.; BOSCHI, A. O. Coração Negro em Revestimentos Cerâmicos: Principais Causas e Possíveis Soluções. Cerâmica Industrial, v. 6, n. 2, p. 12-16, 2001.

DUTRA, R. P. S. A.; GOMES, U. U.; PASKOCIMAS, C. A. Estudo da variação da tonalidade de materiais cerâmicos Tradicionais. Parte III: Efeito da composição Química das Argilas. Encontro Nacional de Tratamento de Minérios e Metalurgia Extrativa, 2005.

EMILIANI, G.P., CORBARA, F. Tecnologia cerâmica. Faenza: Editoriale Faenza Editrice. v.1, p. 198, 1999.

GOMES SOUZA, S. J. Desenvolvimento de massas cerâmicas processadas por via seca com matérias-primas do norte fluminense visando aplicação em revestimento poroso. 2008. 129 f. Tese (Doutorado em Engenharia e Ciência dos Materiais) - Universidade Estadual do Norte Fluminense.

OLIVEIRA, A. P. N. de; HOTZA, D. Tecnologia de Fabricação de Revestimentos Cerâmicos. Florianópolis: Ed. Da UFSC, 2011.

SOUSA, S. J. G.; HOLANDA, J. N. F. Avaliação das propriedades físico-mecânicas de uma massa cerâmica para revestimento poroso (BIII). Cerâmica, v. 51, n. 317, p. 70-76, 2005 . 